\title{
Oral Health Status and Treatment Needs among Factory Employees in Jeddah
}

\author{
Mohammed Shammas ${ }^{1}$, Asmaa Abdullah Bokhari², Rawan Hassan Bukhari ${ }^{3}$, Noof Nawaf AlShareef ${ }^{4}$, \\ Leyana Assem Alradi ${ }^{5}$, Fazeena Karimalakuzhiyil AliKutty ${ }^{6}$, Irfan Adil Majid ${ }^{7}$
}

\begin{abstract}
${ }^{1}$ Department of Prosthodontics, Ibn Sina National College for Medical Studies, Jeddah, Saudi Arabia. ${ }^{2}$ Ibn Sina National College for Medical Studies, Jeddah, Saudi Arabia. ${ }^{3}$ AlFarabi Private Colleges, Jeddah, Saudi Arabia. ${ }^{4}$ Ibn Sina National College for Medical Studies, Jeddah, Saudi Arabia. ${ }^{5}$ Ibn Sina National College for Medical Studies, Jeddah, Saudi Arabia. ${ }^{6}$ Department of Public Health Dentistry, Ibn Sina National College for Medical Studies, Jeddah, Saudi Arabia. ${ }^{7}$ Department of Oral Medicine and Radiology, Ibn Sina National College for Medical Studies, Jeddah, Saudi Arabia.
\end{abstract}

\section{ABSTRACT}

\section{BACKGROUND}

Expatriate workers are employed to work in various sectors in Saudi Arabia on a large scale. Even though various labour laws, schemes and policies are undertaken by the host country, oral health is not given the importance it deserves. This is reflected in factory workers having hidden adverse oral health issues which can hamper their working efficacy and, also their quality of life. In light of aforementioned we conducted this oral health status and treatment needs survey of factory workers in an industrial city of Jeddah, Saudi Arabia.

\section{METHODS}

This was a cross-sectional survey study in which 119 males in the age group 18 to 64 years were included. World Health Organization (WHO) basic oral health survey form was used to extract data regarding the oral examination. The data were analysed using Chi-square test. $\mathrm{P}<0.05$ was considered statistically significant.

\section{RESULTS}

A significant association was seen between different age groups and mobility of teeth ( $\mathrm{p}=0.002)$, between education status and missing teeth $(\mathrm{p}=0.032)$, between frequency of brushing and gingivitis $(\mathrm{p}=0.009)$, between smoking habit and gingivitis $(p=0.000)$ and between smoking habit and missing teeth $(p=0.010)$.

\section{CONCLUSION}

The results of the study showed that most of the factory workers had poor oral and dental health as a result of unawareness and lack of time to seek dental consultation. Primary oral health-care programs like dental screening and oral health education at regular intervals should be made mandatory at factory premises, which will help them maintain their oral health, thus improving their quality of life.

\section{KEY WORDS}

Factory Workers, Oral Health, Oral Health Impact Profile,
Corresponding Author: Dr. Mohammed Shammas, Division of Prosthodontics, Department of Oral and Maxillofacial Rehabilitation, Ibn Sina National College for Medical Studies, Al Mahjar Street, Gulail District, Jeddah-21418, Saudi Arabia. E-mail: mshammas@ibnsina.edu.sa

DOI: $10.14260 /$ jemds/2020/425

How to Cite This Article:

Shammas M, Bokhari AA, Bukhari RH, et al. Oral health status and treatment needs among factory employees in Jeddah. J. Evolution Med. Dent. Sci. 2020;9(27):19521957, DOI: $10.14260 /$ jemds/2020/425

Submission 24-03-2020,

Peer Review 03-06-2020,

Acceptance 10-06-2020,

Published 06-07-2020.

Copyright (c) 2020 JEMDS. This is an open access article distributed under Creative Commons Attribution License [Attribution 4.0 International (CC BY 4.0)] 


\section{BACKGROUND}

Oral health is vital to general wellbeing and oral diseases are one of the most common of non-communicable diseases affecting mankind. It is an important public health problem owing to its prevalence, socio-economical aspect, treatment cost and lack of awareness.[1] Though oral and dental diseases are rarely life-threatening, they have been widely recognized as important cause of negative impact to workers in their daily activities and quality of life ${ }^{[2,3]}$ Regardless of the fact, dental or oral problems also lead to loss of man hours, oral health maintenance continues to be largely neglected.[4]

Jeddah being the second largest and industrialized city of Saudi Arabia hosts a large numbers of industries that employs equally large number of (local and expatriate) workers in them. These workers could be exposed to the hazardous working conditions, which can deteriorate the general and oral health due to the long working hours, continuous day and night shifts, neglected oral hygiene, low socioeconomic status, etc. ${ }^{[5,6]}$ In addition to this, the work contracts of expatriate workers at times may get renewed multiple times, thus, prolonging their stay without annual vacation which takes a toll on their general and oral health. [7]

Although the dental literature documents a large number of studies on oral health of factory employees, seemingly very few of them have been conducted in Asia.[2] Despite the relevance of information to develop oral health strategies that meet the needs of this specific population needs, no studies have reported oral health status and treatment needs of factory workers in the industrial city of Jeddah. Although, prior studies by Sharifa A. M. Al-Shehri in 2012,,[8] Al-Attas et al, in $2014,,^{[9]}$ A H Shah et al in 2015,[10] reported oral health status and treatment needs in Saudi Arabia, they did not target the factory workers in particular. To address the aforementioned knowledge gap, this study was conducted with the aim to assess the oral health status and treatment needs among the factory employees in the industrial city in Jeddah, Saudi Arabia.

\section{METHODS}

\section{Study Design, Setting, and Participants}

This was a cross-sectional study conducted to assess oral health status and treatment needs among factory employees of industrial city in Jeddah, Saudi Arabia. The study was conducted as one day screening camp in the industrial city of Jeddah. The screening camp was organized by the host governmental charity organization working for the welfare of the industrial city employees'. (The host charity organization was chosen because 1) it was logistically challenging to visit all the factories in the industrial city, 2) the host charity organization was located within the industrial city of Jeddah where the industrial city's workers frequently visited). The screening camp was organized on a weekend (non-working day) of December 2018 to collect the study data, because it was convenient to gather the factory workers on the weekend through a prior announcement.
We used the convenient sampling technique for our study because it was difficult to forecast the number of factory employees that would visit the community hall of the host charity organization on the day of screening. Our study participants comprised of all factory workers present in the community hall on the day of screening; who willingly signed an informed consent to be part of the study. Additionally, the following inclusion and exclusion criteria was considered;

\section{Inclusion Criteria}

1. Factory workers who were present at the time of screening.

2. Workers must have worked for at least for six months.

3. Factory workers willing to participate in the study.

\section{Exclusion Criteria}

1. Factory workers who were not able to communicate or cooperate.

2. Factory workers who were below 18 years and above 65 years of age.

\section{Approvals and Ethical Concerns}

Approval to conduct the study was obtained from the host governmental charity organization (looking after the general welfare of factory employees) located in the industrial city. Following the approval of the host charity organization to screen the factory workers for oral health and treatment needs, a formal ethical committee approval was obtained from institutional research ethics review committee (No. H-1806112016).

\section{Training and Calibrating the Examiners}

The examiners participating in the study first were trained and calibrated by experienced staff members to use the modified WHO oral health assessment form (2013). The Kappa value of 0.90 was achieved for intra examiners' reliability.

\section{Data Collection}

The examiners arrived at the predetermined site and day to collect the study data. The trained and calibrated examiners performed Type III oral examination[11] using a standard mouth mirror, probe and adequate ordinary torch light on a comfortable chair with backrest. Demographic details, oral hygiene practices and habits, oral health status and treatment needs was collected through face-to-face interviews and clinical examination respectively. The data was recorded with the help of a trained recording assistant (intern).

\section{Modified WHO Oral Health Assessment Form Included}

1. General information: The demographic data which included the age, gender, education and the marital status.

2. Information about the oral hygiene practices and adverse habits.

3. The oral health status and treatment needs: dental caries, gingivitis, periodontitis, missing teeth, mobility, and teeth that need extraction. 
While screening the study subjects the following variables were measured: number of teeth present; DMFT index; presence and type of removable dentures; and need for immediate care. On an average, examination of each study participant took approximately 15-20 minutes per person. By the end of the day's screening camp we were able to interview and conduct oral examination of 119 subjects.

Following the screening examination, all study participants were provided with dental outpatient visit cards of our institution which gave them access to free dental treatment.

\section{Statistical Methods}

Data of 119 study subjects was analyzed using SPSS (v25.0; IBM, Chicago, IL, USA). Descriptive analysis was carried first, then Chi-square test was used to find an association of dental caries status, mobility, extraction required, missing teeth, gingivitis and periodontitis with age, education, frequency of brushing and smoking habits. $\mathrm{P}<0.05$ was considered statistically significant.

\section{RESULTS}

Independent variables included were age, education, brushing habits, smoking, work experience, etc. and dependent variables of interest were dental caries, missing teeth, mobility, teeth that needed an extraction and oral hygiene status. The study sample included 119 males; the mean age of subjects was 38.00 years $(S D=11.55)$, mean number of decayed teeth were 4.49 ( $\mathrm{SD}=3.48$ ), missing teeth were 3.43 $(\mathrm{SD}=3.94)$, mobile teeth were $3.92(\mathrm{SD}=3.90)$, and extracted teeth were 3.23 ( $\mathrm{SD}=4.41$ ).

Table 1 shows the demographic characteristics of factory workers. There were overall 119 male workers who participated; of them 17 (14.3\%) were in the age group of 1825 years, 41 (34.5\%) were in the age group of 26-35 years, 31 (26.1\%) were in the age group of 36-45 years, $19(16.0 \%)$ were in the age group of 46-55, and 11(9.2) the $>55$ years of age group. Regarding the education status among these factory workers, 39 (32.8\%) did not completed their high school, 63 (52.9\%) completed their high school and 17 (14.3\%) completed their diploma. Total $25(21.0 \%)$ cleaned their teeth twice a day, $56(47.1 \%)$ cleaned their teeth only once and 38 $(31.9 \%)$ cleaned their teeth sometimes. In the study subjects, $44(37.0 \%)$ were smokers and $75(63.0 \%)$ were non-smokers.

\begin{tabular}{|cc|}
\hline Demographics & $\mathbf{N}(\%)$ \\
Age in years & $17(14.3)$ \\
$18-25$ & $41(34.5)$ \\
$26-35$ & $31(26.1)$ \\
$36-45$ & $19(16.0)$ \\
$46-55$ & $11(9.2)$ \\
$>55$ & \\
Education & $39(32.8)$ \\
< high school & $63(52.9)$ \\
High school & $17(14.3)$ \\
Diploma & $25(21.0)$ \\
Frequency of brushing & $56(47.1)$ \\
Twice & $38(31.9)$ \\
Once & \\
Sometimes & $44(37.0)$ \\
Smoking habits & $75(63.0)$ \\
Smoking & \\
Non-smoking &
\end{tabular}

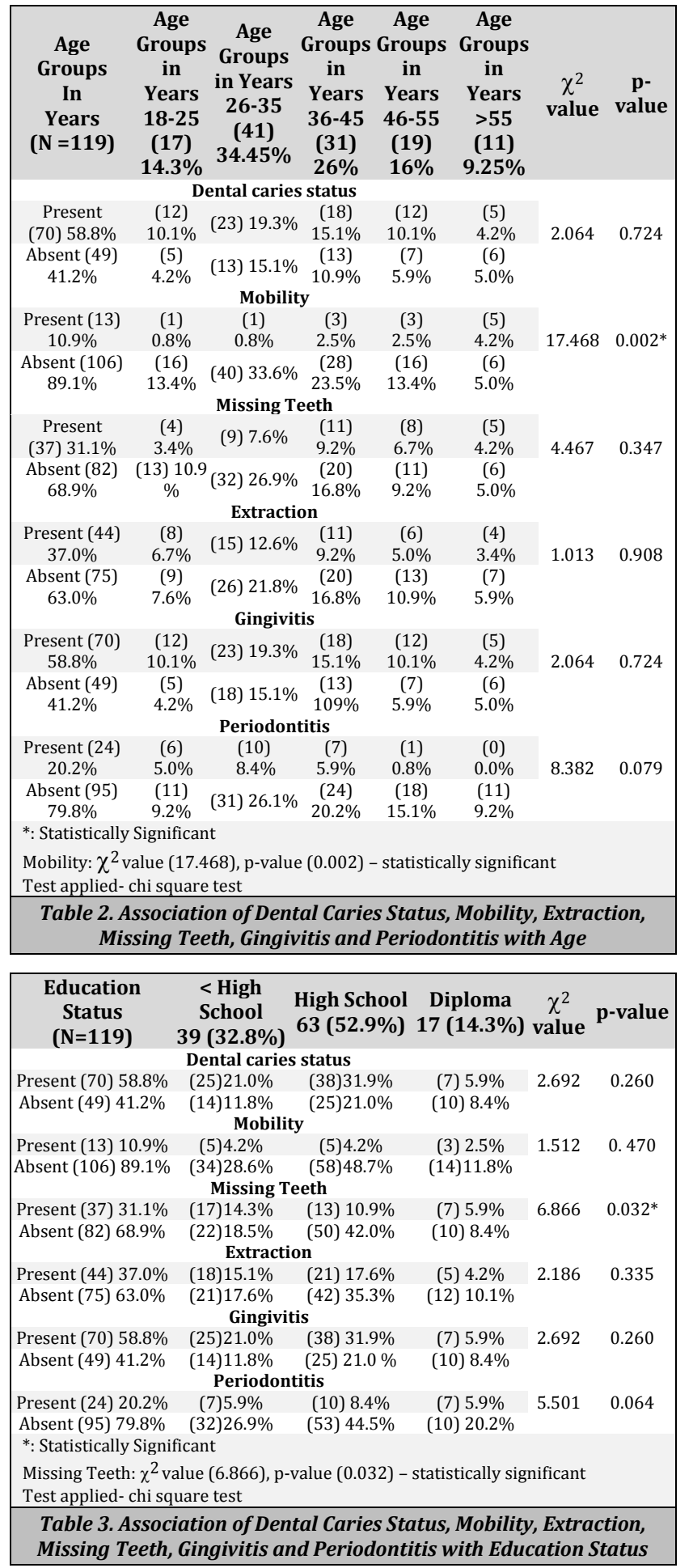

Table 2 shows the association of dental caries, gingivitis, periodontitis, missing teeth, mobility, and extraction with age. A significant association was seen between different age groups and mobility teeth $\left(\chi^{2}=17.468, p=0.002\right)$, whereas no significant association was found among different age groups with dental caries $\left(\chi^{2}=2.064, \mathrm{p}=0.724\right)$, gingivitis $\left(\chi^{2}=8.382\right.$, $\mathrm{p}=0.079)$, periodontitis $\left(\chi^{2}=2.064, \mathrm{P}=0.002\right)$, extraction $\left(\chi^{2}\right.$ $=1.013, \mathrm{p}=0.908)$ and, missing teeth $\left(\chi^{2}=4.467, \mathrm{p}=0.347\right)$.

Table 3 shows the association of dental caries, gingivitis, periodontitis, missing teeth, mobility, and extraction with education status. A significant association was seen between education status and missing teeth $\left(\chi^{2}=6.866, p=0.032\right)$, whereas no significant association was found among different 
age groups with dental caries $\left(\chi^{2}=2.692, p=0.260\right)$, gingivitis $\left(\chi^{2}=5.501, \mathrm{p}=0.064\right)$, periodontitis $\left(\chi^{2}=2.692, \mathrm{p}=0.260\right)$, extraction $\left(\chi^{2}=2.186, \mathrm{p}=0.335\right)$ and, missing teeth $\left(\chi^{2}=6.866, p=0.032\right)$.

\begin{tabular}{|c|c|c|c|c|c|}
\hline $\begin{array}{l}\text { Frequency of } \\
\text { Brushing } \\
(\mathrm{N}=119)\end{array}$ & $\begin{array}{l}\text { Twice (25) } \\
\quad 21 \%\end{array}$ & $\begin{array}{l}\text { Once } \\
\text { (56) } 47 \%\end{array}$ & $\begin{array}{l}\text { Sometimes } \\
\text { (38) } 32 \%\end{array}$ & $\begin{array}{c}\chi^{2} \\
\text { value }\end{array}$ & p-value \\
\hline \multicolumn{6}{|c|}{ Dental caries status } \\
\hline Present (70) 58.8\% & (16) $13.4 \%$ & (33) $27.7 \%$ & (21) $17.6 \%$ & 0.476 & 0.788 \\
\hline \multicolumn{6}{|c|}{ Mobility } \\
\hline Present (13) $10.9 \%$ & (3) $2.5 \%$ & (6) $5.0 \%$ & (4) $3.4 \%$ & 0.038 & 0.981 \\
\hline \multicolumn{6}{|c|}{ Missing Teeth } \\
\hline Present (37) 31.1\% & (9) $7.6 \%$ & (16) $13.4 \%$ & (12) $10.1 \%$ & 0.451 & 0.798 \\
\hline \multicolumn{6}{|c|}{ Extraction } \\
\hline Present (44) $37.0 \%$ & (12) $10.1 \%$ & (17) $14.3 \%$ & (15) $12.6 \%$ & 2.458 & 0.293 \\
\hline \multicolumn{6}{|c|}{ Gingivitis } \\
\hline Present (70) 58.8\% & (16) $13.4 \%$ & (33) $27.7 \%$ & (21) $17.6 \%$ & 0.476 & 0.788 \\
\hline \multicolumn{6}{|c|}{ Periodontitis } \\
\hline $\begin{array}{l}\text { Present (24) } 20.2 \% \\
\text { Absent (95) } 79.8 \% \\
\text { *: Statistically Signif }\end{array}$ & $\begin{array}{l}\text { (2) } 1.7 \% \\
\text { (23) } 19.3 \%\end{array}$ & $\begin{array}{l}\text { (18) } 15.1 \% \\
\text { (38) } 31.9 \%\end{array}$ & $\begin{array}{c}\text { (4) } 3.4 \% \\
\text { (34) } 28.6 \%\end{array}$ & 9.481 & $0.009^{*}$ \\
\hline \multicolumn{6}{|c|}{$\begin{array}{l}\text { Gingivitis: } \chi^{2} \text { value (9.481), p-value (0.009) - statistically significant } \\
\text { Test applied-chi square test }\end{array}$} \\
\hline \multicolumn{6}{|c|}{$\begin{array}{c}\text { Table 4. Association of Dental Caries Status, Mobility, Extraction, } \\
\text { Missing Teeth, Gingivitis and Periodontitis with Frequency of } \\
\text { Brushing }\end{array}$} \\
\hline
\end{tabular}

\begin{tabular}{|c|c|c|c|c|}
\hline $\begin{array}{l}\text { Smoking Habits } \\
(\mathrm{N}=119)\end{array}$ & $\begin{array}{c}\text { Smoking (44) } \\
37 \%\end{array}$ & $\begin{array}{l}\text { Non-Smoking } \\
\text { (75) } 63 \%\end{array}$ & $\chi^{2}$ value & p-value \\
\hline \multicolumn{5}{|c|}{ Dental caries status } \\
\hline Present (70) 58.8\% & (25) $21.0 \%$ & (45) $37.8 \%$ & 0.116 & 0.734 \\
\hline \multicolumn{5}{|c|}{$\begin{array}{l}\text { (19) } 16.0 \% \\
\text { Mobility }\end{array}$} \\
\hline Present (13) 10.9\% & (5) $4.2 \%$ & (8) $6.7 \%$ & 0.014 & 0.906 \\
\hline Absent (106) 89.1\% & \multicolumn{2}{|c|}{ Missing Teeth } & & \\
\hline Present (37) 31.1\% & (20) $16.8 \%$ & (17) $14.3 \%$ & 6.721 & $0.010^{*}$ \\
\hline Absent (82) 68.9\% & $\begin{array}{l}\text { (24) } 20.2 \% \\
\text { Extraction }\end{array}$ & $48.7 \%$ & & \\
\hline Present (44) $37.0 \%$ & (20) $16.8 \%$ & (24) $20.2 \%$ & 2.154 & 0.142 \\
\hline Absent (75) $63.0 \%$ & \multicolumn{3}{|l|}{ Gingivitis } & \\
\hline Present (70) 58.8\% & (25) $21.0 \%$ & (45) $37.8 \%$ & 0.116 & 0.734 \\
\hline Absent (49) $41.2 \%$ & $\begin{array}{l}\text { (19) } 16.0 \% \\
\text { Periodontitis }\end{array}$ & $25.2 \%$ & & \\
\hline Present (24) $20.2 \%$ & (1) $0.8 \%$ & (23) $19.3 \%$ & 13.886 & $0.000^{*}$ \\
\hline Absent (95) 79.8\% & (43) $36.1 \%$ & (52) $43.7 \%$ & & \\
\hline *: Statistically Signific & & & & \\
\hline \multicolumn{5}{|c|}{ Missing Teeth: $\chi^{2}$ value (6.721), $\mathrm{p}$-value $(0.010)$ - statistically significant } \\
\hline \multicolumn{5}{|c|}{$\begin{array}{l}\text { Gingivitis: } \chi^{2} \text { value (13.886), p-value }(0.000) \text { - statistically significant } \\
\text { Test applied-chi square test }\end{array}$} \\
\hline $\begin{array}{l}\text { Table 5. Associa } \\
\text { Missing Teeth, } G\end{array}$ & $\begin{array}{l}\text { tion of Dental Ca } \\
\text { ingivitis and Pel }\end{array}$ & ries Status, Mobi & ility $F$ & io \\
\hline
\end{tabular}

\begin{tabular}{|ccc|}
\hline Type of Intervention & $\begin{array}{c}\text { Number of } \\
\text { Factory } \\
\text { Workers }\end{array}$ & $\begin{array}{c}\text { Percentage of } \\
\text { Factory } \\
\text { Workers }\end{array}$ \\
$\begin{array}{c}\text { No treatment needed } \\
\text { Preventive/routine treatment needed }\end{array}$ & 7 & $5.04 \%$ \\
Prompt treatment needed & 30 & $58.8 \%$ \\
$\begin{array}{c}\text { Immediate treatment needed due to pain or } \\
\text { infection of dental and/or oral origin } \\
\text { Referred for comprehensive evaluation or } \\
\text { medical treatment (systemic condition) } \\
\text { Total }\end{array}$ & 13 & $25.15 \%$ \\
\hline \multicolumn{2}{|c|}{ Table 6. Treatment Need Distribution } \\
\hline \multicolumn{2}{|c|}{} \\
\hline \multicolumn{2}{|c|}{} \\
\hline
\end{tabular}

Table 4 shows the association of dental caries, gingivitis, periodontitis, missing teeth, mobility, and extraction with frequency of brushing. A significant association was seen between frequency of brushing and gingivitis $\left(\chi^{2}=9.481, p=\right.$ 0.009 ), whereas no significant association was found among different age groups with dental caries $\left(\chi^{2}=0.476, p=0.788\right)$, mobility $\left(\chi^{2}=0.038, \mathrm{p}=0.981\right)$, periodontitis $\left(\chi^{2}=0.476\right.$, $\mathrm{p}=0.788)$, extraction $\left(\chi^{2}=2.458, \mathrm{p}=0.293\right)$ and, missing teeth $\left(\chi^{2}=0.451, \mathrm{p}=0.798\right)$.
Table 5 shows the association of dental caries, gingivitis, periodontitis, missing teeth, mobility, and extraction with smoking habit. A significant association was seen between smoking habit and gingivitis $\left(\chi^{2}=13.886, p=0.000\right)$ and missing teeth $\left(\chi^{2}=6.721, p=0.010\right)$, whereas no significant association was found among different age groups with dental caries $\left(\chi^{2}=0.116, \mathrm{p}=0.734\right)$, mobility $\left(\chi^{2}=0.014\right.$, $\mathrm{p}=0.906)$, periodontitis $\left(\chi^{2} 0.116, \mathrm{p}=0.734\right)$, and extraction $\left(\chi^{2}=2.154, \mathrm{p}=0.734\right)$.

Table 6 shows the treatment needs of the study subjects we screened. More than half $(58.8 \%)$ of the study subjects needed some form of preventive/routine treatment. Only $5.04 \%$ of the study subjects did not need any treatment. Whereas, no one among the study subjects needed referral for any form of comprehensive evaluation or medical treatment (systemic condition).

\section{DISCUSSION}

The extent of industrial growth reflects the growth of a nation, the workers in the industries constitute a significant proportion of the total population who work and live in a highly complicated environment. Therefore, the health of this population reflects the health of the society in the given area.[12] The factors affecting the oral health of an individual could be various including environmental, occupational, dietary and pathologic factors, and the oral hygiene practices of an individual. The factory employees' poor oral health condition could be because of a lack of medical and dental health care facilities in the factory premises.

The present study was conducted to assess the oral health status and treatment needs among factory employees in Jeddah, Saudi Arabia. The study subjects were all permanent employees of the various factories, and all were males. The association of dental caries status, mobility, extraction, missing teeth, gingivitis and periodontitis with age, education status, frequency of brushing, and the smoking habit were assessed.

In this study majority (41\%) of industrial workers were in the age group of 26-35, which is similar to other study reported by Bansal and Veeresha,,2] followed by $31 \%$ in the age group of 36-45 which was similar to other studies by Tomita et al [13] and Umoh and Azodo.[14]

Almost all subjects in our study brushed their teeth at least once in a day, which was similar to the results of a study by Patil et al[6] and Eldarrat et al.[15] However, in the present study, a higher number of smokers used to brush their teeth. This study revealed that more than $80 \%$ of the study subjects used toothbrushes to brush their teeth; this is in agreement with findings of a study conducted by Patil et al.[6]

A majority of the factory workers in the present study did not use any form of tobacco or related products, which was contrary to the findings of a study reported by Sood et al[4] and Sanadhya et al.[16] the only other study that reported similar results was Patil et al (31.4\% study subjects used tobacco).[6] However, many other studies have reported higher rate of smoking among the employees.'[17-19]

Caries frequency in our study was similar to that reported by Ahlberg et al.[20] which was less in comparison with Bachanek et al findings ${ }^{[21]}$ and the percentage of subjects, 
which were caries free were remarkably higher than reported by Duraiswamy et al.[22] Bansal and Veeresha[2] and Hayashi[23] reported much higher frequency of missing teeth than our study, likewise the age group with higher frequency of missing teeth was in the range of $36-45$ years which is in contrast to the aforementioned studies. The number of missing teeth were significantly less in subjects who were educated (high school and diploma) and were non-smokers.[22]

The frequency of gingivitis in our study was similar to the findings of Cristina Gomes De Mcedo et al.[3] and Khurana et al.[24] these finding were in contrast with the finding of Singh et al.[25] In contrast to the reports of Srikandi and Clarke,[26] our study reported less amount of periodontal disease. Therefore, our findings were in agreement with that of Bansal and Veeresha.[2] The frequency of periodontitis was significantly less in subjects who brushed their teeth at least once daily and did not smoke.

The most predominant treatment need in our study was restoration of decayed teeth followed by oral prophylaxis similar to the report of Roman and Pop.[27]

From 119 factory workers, only 5.04\% did not need any treatment, while the remaining $94.96 \%$ needed some form of treatment. About $58.8 \%$ of the study population needed preventive or routine treatment, nearly $25.15 \%$ required prompt treatment and $10.9 \%$ needed immediate treatment these findings were in contrast with other studies by Sandhaya et al which reported that, only $3.5 \%$ subjects required preventive care and $27.4 \%$ required immediate treatment,[16] while Singh M et al reported only $22.4 \%$ required preventive or routine treatment, while $62.4 \%$ required prompt treatment.[17]

\section{Limitations}

The conclusions of the current study should be interpreted bearing in mind the following limitations;

1. The study sample: the sampling (convenient) technique and the sample size was small, as only those who were present in the community hall of the hosting charity organization on the day of screening and gave the informed consent were considered as study subjects.

2. Information on tobacco was collected based on the participant's self-reported information. This probably could have caused a memory bias.

3. The duration of working in the factory was also not documented, which plays a vital role in assessing the occupational effects on oral health.

4. Type of work involved in the factory was not documented, as it may play a role in the exposure to hazardous work environment leading to general and oral diseases.

\section{CONCLUSIONS}

Industrial development plays a key role in a nation's development, and the factory employees are its lifeline. These employees' work in unique, testing, and sometimes compromising work conditions. Although the factory workers form the lifeline of an industry, they get neglected at times. Our study revealed a high prevalence of dental caries and periodontal diseases, hence a high percentage of treatment- need in the factory employees we screened. Prior studies worldwide have revealed that oral disease and occupational hazards are omnipresent; therefore, a comprehensive preventive program overarching the general and oral wellbeing of this risk group should be in place that underpins the special emphasis on preventing factors that contribute to their occurrence. On campus, access to medical and dental screening and regular health education/promotion programs could prevent the build-up of healthcare needs of factory workers.

The authors would like to thank the community service center of Ibn Sina National College for Medical Studies for extending their help and support in organizing and conducting the screening program on our request. We would like to thank the host charity organization located in the industrial city of Jeddah for their logistic support in organizing the screening camp. We would to thank Dr. Saravanan R, Dr. Sheetal Kumar, Dr. Maher Babsail, Dr. Mohammed Zabedi, and Dr. Venugopal Seemakurthi, interns of 2017-18 batch for their help in screening the patients.

\section{REFERENCES}

[1] Petersen PE. Dental visits, dental health status and need for dental treatment in a Danish industrial population. Scand J Soc Med 1983;11(2):59-64.

[2] Bansal M, Veeresha KL. Oral health status and treatment needs among factory employees in Baddi-BarotiwalaNalagarh Industrial hub, Himachal Pradesh, India. Indian J Oral Sci 2013;4(3):105-9.

[3] De Macedo CG, de Paula QD. Quality of life and selfperceived oral health among workers from a furniture industry. Braz J Oral Sci 2011;10(4):226-32.

[4] Sood M, Blaggana A, Vohra P, et al. Periodontal status of smoker and non-smoker ceramic factory workers. J Innov Dent 2011;11(3):1-6.

[5] Sudhanshu S, Pankaj A, Sorabh J, et al. Dental diseases of acid factory workers globally-narrative review article. Iran J Public Health 2014;43(1):1-5.

[6] Patil VV, Shigli K, Hebbal M, et al. Tooth loss, prosthetic status and treatment needs among industrial workers in Belgaum, Karnataka, India. J Oral Sci 2012;54(4):285-92.

[7] Naithani P, Jha AN. Challenges faced by expatriate workers in the Gulf Cooperation Council countries. Int J Bus Manag 2009;5(1):98-104.

[8] Al-Shehri SA. Oral health status of older people in residential homes in Saudi Arabia. Open Journal of Stomatology 2012;2(4):307-13.

[9] Al-Attas SA, Ibrahim SS, Amer HA, et al. Prevalence of potentially malignant oral mucosal lesions among tobacco users in Jeddah, Saudi Arabia. Asian Pac J Cancer Prev 2014;15(2):757-62.

[10] Shah AH, Bindayel NA, AlOlaywi FM, et al. Oral health status of a group at a special needs centre in AlKharj, Saudi Arabia. J Disabil Oral Health 2015;16(3):79-85.

[11] Thompson NJ, Boyer EM. Validity of oral health screening in field conditions: pilot study. J Dent Hyg 2006;80(2):9.

[12] Khalil L, Khanam S. Health conditions of lock industry workers: a case study of Aligarh City. Iran J Basic Med Sci 2012;1:1-7. 
[13] Tomita NE, Chinellato LEM, Lauris JRP, et al. Oral health of building construction workers: an epidemiological approach. J Appl Oral Sci 2005;13(1):24-7.

[14] Umoh AO, Azodo CC. Association between periodontal status, oral hygiene status and tooth wear among adult male population in Benin City, Nigeria. Ann Med Health Sci Res 2013;3(2):149-54.

[15] Eldarrat A, Alkhabuli J, Malik A. The prevalence of selfreported halitosis and oral hygiene practices among Libyan students and office workers. Libyan J Med 2008;3(4):170-6.

[16] Sanadhya S, Nagarajappa R, Sharda AJ, et al. The oral health status and the treatment needs of salt workers at Sambhar lake, Jaipur, India. J Clin Diagn Res 2013;7(8):1782-6.

[17] Gazdek D, Samardžić S. Croatian smoke-free law and smoking habits among employees of health care facilities in Koprivnica-Križevci County. Croat Med J 2013;54(4):407-10.

[18] Stojanović M, Mušović D, Petrović B, et al. Smoking habits, knowledge about and attitudes toward smoking among employees in health institutions in Serbia. Vojnosanit Pregl 2013;70(5):493-500.

[19] Choi SH, Pohl JM, Terrell JE, et al. Factors associated with smoking among operating engineers. Workplace Health Saf 2013;61(9):385-92.
[20] Ahlberg J, Ahlberg J, Tuominen R, et al. Subsidized dental care improves caries status in male industrial workers. Community Dent Oral Epidemiol 1996;24(4):249-52.

[21] Bachanek T, Pawlowicz A, Tarczydlo B, et al. Evaluation of dental health in mill workers. Part I. The state of dentition. Ann Agric Environ Med AAEM 2001;8(1):103-5.

[22] Duraiswamy P, Kumar TS, Dagli RJ, et al. Dental caries experience and treatment needs of green marble mine laborers in Udaipur district, Rajasthan, India. Indian J Dent Res 2008;19(4):331-4.

[23] Hayashi N, Tamagawa H, Tanaka M, et al. Association of tooth loss with psychosocial factors in male Japanese employees. J Occup Health 2001;43(6):351-5.

[24] Khurana S, Jyothi C, Dileep CL, et al. Oral health status of battery factory workers in Kanpur city: a cross-sectional study. J Indian Assoc Public Health Dent 2014;12(2):80-7.

[25] Singh M, Ingle NA, Kaur N, et al. Oral health status and treatment needs of lock factory workers in Aligarh city. J Adv Oral Res 2015;6(2):28-32.

[26] Srikandi TW, Clsrke NG. Periodontal status in a South Australian industrial population. Community Dent Oral Epidemiol 1982;10(5):272-5.

[27] Roman A, Pop A. Community periodontal index and treatment needs values (CPITN) in a factory worker group in Cluj-Napoca, Romania. Int Dent J 1998;48(2):123-5. 